Độ mô học biệt hóa vừa chiếm tỷ lệ cao nhất, đa số bệnh được phát hiện ở giai đoạn muộn. Có mối liên quan giữa hoại tử bẩn, nảy chồi và xâm nhâpp lympho trong biểu mô với độ xâm lấn. Cụ thể, những trường hợp u ở giai đoạn T3 và T4 có tỷ lệ hoại tử bẩn, nảy chồi cao hơn ở giai đoạn $T 1$ và $T 2$. Trong khi đó, ở giai đoan $T 1$ và $T 2$ tỷ lệ xâm nhập lympho trong biểu mổ lại cao hơn ở giai đoạn $\mathrm{T} 3$ và $\mathrm{T} 4$.

\section{TÀI LIÊU THAM KHẢO}

1. Betge J, Pollheimer $M$, Lindtner $R A$, et al. (2012), Intramural and extramural vascular invasion in colorectal cancer: prognostic significance and quality of pathology reporting, Cancer, 118(3): 628-38.

2. Bosman FT, Carneiro F, Hruban $\mathrm{RH}$, et al. (2010), WHO classification of tumours of the digestive system, vol. 3. 4th ed Lyon: International Agency for Research on Cancer.

3. Bray F, Ferlay J, Soerjomataram I, Siegel RL,
Torre LA, Jemal A. (2018) Global cancer statistics 2018: GLOBOCAN estimates of incidence and mortality worldwide for 36 cancers in 185 countries. CA Cancer J Clin. 68(6):394-424.

4. Chu Văn Đức (2015), Nghiên cứu bốc lộ môt sô dấu ấn hóa mô miến dịch và mối liên quan với đặc điểm mô bệnh hoc trong ưng thư biểu mô đại trự̛c tràng, Luân An tiến sĩ, Đai hoc Y Hà Nôi.

5. Đăng Trần Tiến (2007), Nghiên cứu hình thái hóc của ung thư đai trực tràng, Tap chí Y hoc TP Hồ Chí Minh, 11(3):86-88.

6. Marzouk $O$ and Schofield J (2011), Review of histopathological and molecular prognostic features in colorectal cancer, Cancers (Basel), 3(2):2767-810.

7. Nakamura T, Mitomi H, Kanazawa $H$, et al. (2008), Tumor budding as an index to identify high-risk patients with stage II colon cancer, Dis Colon Rectum, 51(5):568-72.

8. Nguyễn Văn Hồng (2011), Nghiên cứu đăcc điểm mô bênh học và hóa mô miễn dịch (Ki67 và $\mathrm{p} 53$ ) ung thư đại trực tràng tại bênh viện 19.8 - Bộ Công An, Đề tài nghiên cứu cấp Bộ.

\title{
NGHIÊN CỨU TÁC DỤNG CỦA TRÀ NHÚNG BTL VÀ TƯ VẤN TRONG ĐIỀU TRI CAI NGHIỆN THUỐC LÁ
}

\section{TÓM TẮT}

Mục tiêu: Đánh giá tác dụng điều trị Hội chứng cai trong cai nghiện thuốc lá của trà nhúng BTL và tư vấn, theo dõi tác dụng không mong muốn của phương pháp can thiệp. Đối tượng và phương pháp: thử nghiệm lâm sàng tiến cứu, so sánh trước và sau điều tri. Đối tướng là 200 bênh nhân. Liêu trình điêuu trị là 30 ngày. Kết quả: Cai nghiện thuốc lá đạt tỷ lệ 38\% tốt, $25 \%$ khá và $37 \%$ không kết quả. Kểt lựận: Trà nhúng BTL kết hợp tư vấn có tác dụng hố trợ cai nghiện thuốc lá, cải thiên các triệu chứng của Hội chứng cai: thèm thuốc, lio lắng,căng thẳng, cáu gắt, giảm tập trung, tăng cân... và làm giảm hàm lượng CO trong hơi thở của bệnh nhân sau cai nghiện thuốc lá.

Tư khóa: Cai nghiện thuốc lá, Hội chứng cai, trà nhúng BTL, tư vấn

\section{SUMMARY}

STUDY THE EFFICIENCY OF SMOKING CESSATION THROUGH THE BLT TEA AND MEDICAL ADVICE

Objectives: To determine the effectiveness of BTL tea and giving medical advice in smoking cessation treatment and monitor methods' adverse

${ }^{1}$ Bệnh viện Y học cổ truyền Trung ương

Chịu trách nhiệm chính: Trân Thái Hà

Email: phdtranthaiha@gmail.com

Ngày nhận bài: 9.9.2021

Ngày phản biên khoa hoc: 8.11.2021

Ngày duyệt bài: 12.11.2021

\section{Trần Thái Hà ${ }^{1}$, Bùi Thị Phương Thảo ${ }^{1}$}

reaction. Subjects and Methods: Perspective clinical trial, comparisons of before and after treatment. There are 200 patients in the 30-day treatment. Results: The very good rate of smoking cessation cases were $38 \%, 25 \%$ of these were good and $37 \%$ of these were not effective. Conclusions: BTL tea and medical advice is effective in smoking cessation, improving symptoms of withdrawal syndrome (shortness, irritability, insomnia, cravings...) and decreased levels of $\mathrm{CO}$ in the breath of patients after treatment.

Keywords: Smoking cessation, withdrawal syndrome, BTL tea, medical advise

\section{I. ĐẶT VẤN ĐỀ}

Trên thế giới hiện có khoảng 1,3 tỷ người hút thuốc lá. Việt Nam vẫn là một trong 15 nước có số người hút thuốc lá cao nhất trên thế giới. Theo kết quả điều tra GATS (2015) (điều tra tình hình sử dụng thuốc lá ở người trưởng thành), Việt Nam hiện có $22,5 \%$ dân số trên 15 tuối đang hút thuốc lá, tương đương với 15,6 triệu người [1]. Mỗi năm, tại Việt Nam có khoảng 40.000 ca tử vong liên quan đến sử dụng thuốc lá, nếu không có biện pháp phòng chông tích cực con số này sẽ là 70.000 vào năm 2030 [2].

Thuốc lá gây ra những tổn thất về kinh tế và sức khỏe đối với các cá nhân, gia đình và xã hội. Trên thế giới, ước tính mỗi năm sử dụng thuốc lá gây thiệt hại khoảng 500 tỷ đô-la Mỹ. Tại Việt 
Nam, năm 2012 người dân Việt Nam đã chi 22 nghìn tỷ đồng cho mua thuốc lá, chưa kể các chi phí do bệnh lý mà hút thuốc lá gây ra là hơn 23 tỷ đồng mỗi năm [2].

Nhằm khắc phục những tác hại về kinh tế, xã hội và sức khỏe do thuốc lá gây ra tại các quốc gia cũng như trên toàn thế giới đã có những nỗ lực đầu tư cho các chương trình phòng chống tác hại của thuốc lá với mục tiêu kiểm soát và giảm tỷ lệ hút thuốc. Đã có nhiều biện pháp hỗ trợ cai nghiện thuốc lá như sử dụng viên dán nicotine, laser, tâm lý liệu pháp... nhưng kết quả còn thấp và tỳ lệ tái nghiện thuốc lá vẫn còn cao. Y học cổ truyền cũng có nhiều nghiên cứu sử dụng các biện pháp như châm cứu, xoa bóp bấm huyệt, dùng chế phẩm YHCT kết hợp với tư vấn để điều trị nghiện thuốc lá với bước đầu được đánh giá tích cực.

Năm 2018, Tại Bệnh viện $Y$ học cổ truyền Trung Ương triển khai đề tài viên ngậm CTL kết hợp tư vấn trong điều trị nghiện thuốc lá cho thấy tỷ lệ cai thuốc lá thành công sau 35 ngày đạt 35\% [4]. Tuy nhiên, qua sử dụng nhiều bệnh nhân vẫn chưa thích nghi được với mùi hắc của vị thuốc đồng thời người nghiện thuốc lá có cảm giác phải uống thuốc từ đó gây ra tâm lý mặc cảm cho người sử dụng. Bệnh nhân khi cai nghiện thuốc lá thường có biểu hiện nhạt miệng, họng khô, rát, ho dai dẳng, tiết nhiêu đờm, giá cúm... Chính vì vậy, trà nhúng BTL được xây dựng trên cơ sở thành phần viên ngậm CTL gia thêm 2 vị Trần bì và Kim ngân hoa (Trần bì có tác dụng lý khí hóa đờm, táo thấp hành trệ dùng để trị ho, tiêu đờm, nôn và buồn nôn, đầy bụng, chán ăn. Kim ngân hoa có tác dụng thanh nhiệt giải độc, sát trùng dùng để trị ho do phế nhiệt, hạ sốt). Mặt khác, sản phẩm được làm dưới dạng trà nhúng rất dễ sử dụng, dễ mang theo và đặc biệt phù hợp với tâm lý sử dụng của người nghiện thuốc lá. Đề tài "Nghiên cứu tính an toàn và tác dụng điều trị nghiện thuốc lá của trà nhúng BTL" được tiến hành với 2 mục tiêu:

1. Đánh giá độc tính cấp và bán trường diễn của trà nhúng BTL trên thực nghiệm.

2. Đánh giá tác dung của trà nhúng BTL kêt hợp tư vấn trong điều trị nghiện thuốc lá trên lầm sàng và một số chỉ số cận lầm sàng.

\section{CHẤT LIỆ, ĐỐI TƯợNG VÀ PHƯƠNG PHÁP NGHIÊN CỨU}

2.1. Chất liệu nghiên cứu

- Chất liệu nghiên cứu: Trà nhúng BTL

Nơi sản xuất: Khoa Dược - Bệnh viện $Y$ học Cổ truyền Trung ương.
Dạng bào chế: trà nhúng (3g/túi).

Quy cách đóng gói: Hộp 30 túi

Hạn sử dung: 2 năm kể từ ngày sản xuất

Tiêu chuẩn sản xuất: Đạt tiêu chuẩn cơ sở.

Cách sử dụng: Ngày uống 3 gói, mỗi lần uống 01 gói, pha nước uống trong ngày hoặc uống khi thây thèm thuốc.

2.2. Đối tượng nghiên cứu. Gồm 200 bệnh nhân được chẩn đoán nghiện thuốc lá được điều trị tại Phòng tư vấn cai nghiện thuốc lá Bệnh viện Y học cổ truyền Trung ương.

- Thời gian nghiên cứu: Từ tháng 6 năm 2020 đến tháng 10 năm 2020.

- Tiêu chuẩn chọn bệnh nhân:

- Chọn bệnh nhân nghiện thuốc lá không phân biệt giới tính, nghề nghiệp, tuổi từ 18 - 80 .

- Mức độ quyết tâm cai thuốc lá đánh giá theo bảng Q-MAT $\geq 7$ điểm.

- Tiêu chuẩn nghiện thuốc lá được chẩn đoán theo DSM - IV[6]:

- Tiêu chuẩn loại trừ:

Người nghiện thuốc lá là nữ đang có thai hoặc cho con bú.

Người nghiện thuốc lá có kèm theo các bệnh như: viêm phổi, lao, suy gan, suy thận, ung thư', HIV, tâm thần.

Người nghiện thuốc lá không hợp tác, bỏ điều trị, không thực hiện các quy định trong nghiên cứu, người nghiện không đồng ý tham gia nghiên cứu.

\subsection{Phương pháp nghiên cứu}

- Ngày đầu tiên đến khám (D0): Người nghiện thuốc lá được phát bộ phiếu điều tra, khám lâm sàng, làm xét nghiệm cận lâm sàng: công thức máu, sinh hóa máu (AST, ALT, ure, creatinin), đo nồng độ $\mathrm{CO}$ trong hơi thở, theo một mẫu bệnh án thống nhất (Phụ lục).

Người nghiện thuốc lá được tư vấn cai nghiện thuốc lá cùng với điều tra viển. Thời gian tư vấn từ 15 - 30 phút và được cung cấp số điện thoại hỗ trợ cai nghiện thuốc lá của Bệnh viện $Y$ học cổ truyền Trung ương.

Phát trà cho bệnh nhân, mỗi ngày uống 3 gói trà nhúng $B T L$, mỗi lần 1 gói, pha nước uống trong ngày.

- Liệu trình điều trị 30 ngày liên tục, mỗi bệnh nhân được đánh giá các chỉ số lâm sàng vào ngày: D0, D7, D14, D21, D30.

- Nồng độ khí CO: Theo dõi tại các thời điểm: D0, D7, D14, D21, D30, đánh giá trước và sau điều trị.

- Đánh giá các chỉ số cận lâm sàng: công thức máu, hóa sinh máu, nước tiểu, nội soi tai mũi họng, điện tim, siêu âm ổ bụng, XQ tim phổi 
thẳng vào ngày: $\mathrm{D} 0, \mathrm{D} 30$.

2.4. Chỉ tiêu theo dõi và đánh giá kết quả

2.4.1. Các chỉ tiêu đánh giá kêt quả điều trị:

- Sự cải thiện các triệu chứng của hội chứng cai

- Thay đổi nồng độ khí $\mathrm{CO}$ trước và sau điều trị

- Đánh giá kết quả dựa trên thang điểm MPSS

- Đánh giá kết quả dựa trên nồng độ $C O$

- Sự thay đổi số điếu thuốc lá mối ngày trước, sau điểu trị

2.4.2. Các chỉ tiêu đánh giá tác dụng không mong muốn

III. KẾT QUẢ NGHIÊN CỨU

3. 1. Sự cải thiện các triệu chứng của hội chứng cai

Bảng 3.1. Các triệu chứng của hối chứng cai

\begin{tabular}{|c|c|c|c|c|c|}
\hline Triệu chứng & D0 & D7 & D14 & D21 & D30 \\
\hline Thèm thuốc & $192(96 \%)$ & $174(87 \%)$ & $143(71.5 \%)$ & $74(37 \%)$ & $25(12.5 \%)$ \\
\hline Lo lắng & $2(1 \%)$ & 0 & 0 & 0 & 0 \\
\hline Căng thắng & $3(1.5 \%)$ & $3(1.5 \%)$ & $2(1 \%)$ & 0 & 0 \\
\hline Cáu gắt & $6(3 \%)$ & $2(1 \%)$ & 0 & 0 & 0 \\
\hline Giảm tập trung & $16(8 \%)$ & $5(2.5 \%)$ & $4(2 \%)$ & $3(1.5 \%)$ & $1(0.5 \%)$ \\
\hline Mất ngủ & $46(23 \%)$ & $32(16 \%)$ & $20(10 \%)$ & $12(6 \%)$ & $7(3.5 \%)$ \\
\hline Đau đâu & $12(6 \%)$ & $11(5.5 \%)$ & $9(4.5 \%)$ & $6(3 \%)$ & $2(1 \%)$ \\
\hline Ho & $12(6 \%)$ & $2(1 \%)$ & $4(2 \%)$ & $2(1 \%)$ & $2(1 \%)$ \\
\hline Ngứa họng & $3(1.5 \%)$ & $1(0.5 \%)$ & $1(0.5 \%)$ & 0 & 0 \\
\hline Tăng cần & 0 & $1(0.5 \%)$ & $3(1.5 \%)$ & $3(1.5 \%)$ & $5(2.5 \%)$ \\
\hline Khác & 0 & 0 & 0 & 0 & 0 \\
\hline
\end{tabular}

Nhân xét: Nhìn vào kết quả của bảng 3.1 ta thấy các triệu chứng của hội chứng cai xuất hiện nhiêuu nhất vào ngày đầu và ngày thứ 7 sau khi cai thuốc lá, các triệu chứng cai thường gặp nhất là thèm thuốc, giảm tập trung, mất ngủ, đau đầu, ngứa họng, tăng cân. Phương pháp cai thiệp làm giảm rõ rệt triệu chứng của hội chứng cai, các triệu chứng này bắt đầu giảm từ ngày thứ 14 và giảm mạnh vào ngày thứ 21 .

3.3. Nồng độ khí $\mathrm{CO}$ trước và sau điêu trị:

Bảng 3.2. Nồng độ khí CO trước và sau điều trị

\begin{tabular}{|c|c|c|}
\hline & Ngày & Nồng đô khí CO (ppm) \\
\hline & D0 & $16.74 \pm 3.41$ \\
\hline & D7 & $14.38 \pm 3.35$ \\
\hline & D14 & $12.32 \pm 2.84$ \\
\hline & $\mathrm{D} 21$ & $10.08 \pm 3.01$ \\
\hline & D30 & $7.72 \pm 3.66$ \\
\hline & Sau 7 ngày & $<0.05$ \\
\hline p & Trước sau & $<0.05$ \\
\hline
\end{tabular}

Nhân xét: Dựa vào kết quả bảng 3.30 ta nhận thấy nồng độ khí CO trong máu bệnh nhân giảm rõ rệt sau 7 ngày giảm từ $16.74 \pm 3.41$ xuống còn $14.38 \pm 3.35$, và sau 30 ngày chỉ số này giảm còn $7.72 \pm 3.66$

Kết quả này có ý nghĩa thống kê với $p$ sau 7
- Tác dụng không mong muốn: mẩn ngứa dị ứng, buồn nôn nôn, rối loạn tiêu hóa.

- Cận lâm sàng:

- Thay đổi công thức máu, hóa sinh máu trước và sau điều trị

- Thay đổi chỉ số nước tiểu

- Thay đổi hình ảnh nội soi tai mũi họng, siêu âm ổ bụng, điện tim, XQ tim phổi thẳng.

2.5. Xử lý số liệu: Theo phương pháp thống kê dùng trong y sinh học SPSS 20.0
- Lâm sàng: ngày và $\mathrm{p}$ trước sau điều trị đều $<0.05$.

3.4. Đánh giá kết quả dưa trên nồng độ $\mathrm{CO}$ Bảng 3.3. Đánh giá kểt quả điều trị

\begin{tabular}{|c|c|c|}
\hline Kết quá & $\mathbf{n}$ & $\mathbf{\%}$ \\
\hline Tốt & 76 & 38.0 \\
\hline Khá & 50 & 25.0 \\
\hline Không kết quả & 74 & 37.0 \\
\hline $\boldsymbol{\Sigma}$ & $\mathbf{2 0 0}$ & $\mathbf{1 0 0 . 0}$ \\
\hline
\end{tabular}

Nhận xét: Kết quả nồng độ khí CO kết quả tốt khá chiếm tỷ lệ $63 \%$

3.4. Đánh giá kết quả dựa trên thang điểm MPSS

Bảng 3.4. Thang điểm MPSS

\begin{tabular}{|c|c|c|}
\hline Kết quả & $\mathbf{n}$ & $\mathbf{\%}$ \\
\hline Tốt & 62 & 31.0 \\
\hline Khá & 87 & 43.5 \\
\hline Trung bình & 44 & 22.0 \\
\hline Kém & 7 & 3.5 \\
\hline $\mathbf{\Sigma}$ & $\mathbf{2 0 0}$ & $\mathbf{1 0 0 . 0}$ \\
\hline
\end{tabular}

Nhận xét: Tỷ lệ khá tốt chiếm tỷ lệ là $74.5 \%$

3.5. Tác dụng không mong muốn trên lâm sàng

\begin{tabular}{|c|c|c|}
\hline $\begin{array}{c}\text { Tác dụng không } \\
\text { mong muốn }\end{array}$ & $\mathbf{n}$ & Tỷ lệ \% \\
\hline Mấn ngứa, di ứng & 0 & 0 \\
\hline Buồn nôn, nôn & 0 & 0 \\
\hline Rối loạn tiêu hóa & 0 & 0 \\
\hline
\end{tabular}


Nhận xét: Nhìn vào bảng 3.5 cho thấy sử dụng trà nhúng BTL trên bệnh nhân cai nghiện thuốc lá không ghi nhận tai biến xảy ra.

\subsection{Tác dụng không mong muốn trên cận lâm sàng}

Bảng 3.6. Thay đổi công thức máu, hóa sinh máu trước và sau điều trị

\begin{tabular}{|c|c|c|c|}
\hline \multirow[b]{2}{*}{ Chỉ số theo dõi } & \multicolumn{2}{|c|}{$X \pm S D$} & $\mathbf{p}$ \\
\hline & DO & D30 & \multirow{13}{*}{$>0.05$} \\
\hline Hồng câu (T/I) & $4.93 \pm 0.61$ & $4.95 \pm 0.66$ & \\
\hline Bạch câu (G/I) & $7.56 \pm 1.99$ & $7.42 \pm 1.46$ & \\
\hline Tiếu cầu (G/I) & $238.29 \pm 54.76$ & $239.84 \pm 52.49$ & \\
\hline Glucose $(\mathrm{mmol} / \mathrm{l})$ & $5.78 \pm 1.25$ & $5.72 \pm 1.07$ & \\
\hline Cholesterol $(\mathrm{mmol} / \mathrm{l})$ & $4.87 \pm 1.00$ & $4.86 \pm 0.94$ & \\
\hline Triglycerid (mmol/l) & $2.46 \pm 2.40$ & $2.30 \pm 1.89$ & \\
\hline $\mathrm{HDL}$ & $1.26 \pm 0.50$ & $1.25 \pm 0.49$ & \\
\hline LDL & $2.55 \pm 0.86$ & $2.52 \pm 0.81$ & \\
\hline Ure (mmol/l) & $5.41 \pm 1.28$ & $5.39 \pm 1.15$ & \\
\hline Creatinin $(\mu \mathrm{mol} / \mathrm{l})$ & $90.50 \pm 14.80$ & $90.66 \pm 14.03$ & \\
\hline GPT $(\mathrm{U} / \mathrm{I})$ & $43.91 \pm 13.18$ & $43.64 \pm 13.65$ & \\
\hline GOT (U/I) & $25.31 \pm 12.08$ & $25.37 \pm 11.84$ & \\
\hline
\end{tabular}

Nhận xét: Nhìn vào kết quả của các bảng 3.6 ta thây không có sự thay đổi nào có ý nghĩa thống kê trước và sau điều trị đối với các chỉ số hồng cầu, bạch cầu, tiểu cầu và các chỉ số sinh hóa máu với $p$ đều $>0.05$.

\section{BÀN LUẬN}

4.1 Cải thiên triệu chứng lâm sang. Kết quả bảng 3.1 cho thấy phương pháp điêu trị cai nghiện thuốc lá bằng trà nhúng BTL có tác dụng cải thiện các triệu chứng lâm sàng do hội chứng cai gây ra.

Các triệu chứng này xuất hiện nhiều nhất vào ngày đầu và ngày thứ 7 sau khi cai thuốc lá, các triệu chứng thường gặp nhất là: thèm thuốc, lo lắng, căng thẳng, cáu gắt, giảm tập trung, mất ngủ, tăng cân...., khi áp dụng phương pháp cai thiệp các triệu chứng cai bắt đâuu giảm đáng kể từ ngày thứ 14 và giảm mạnh vào ngày thứ 21 . Ngày đầu khi cai nghiện thuốc lá tỷ lệ bệnh nhân thèm thuốc rất cao $96 \%$, mất ngủ $23 \%$, giảm tập trung $8 \%$, ho, đau đầu, cáu gắt $6 \%$. Sau 7 ngày điều trị, đây là thời kỳ khó khăn nhất của người cai, nồng độ nicotin trong máu bắt đầu giảm xuống, các triệu chứng khó chịu của hội chứng cai bắt đầu biểu hiện nhiều hơn, tỷ lệ thèm thuốc giảm xuống còn $87 \%$, và bắt đầu xuất hiện các triệu chứng khác của hội chúng cai như tăng cân... ở một số bệnh nhân. Đến ngày 14, người cai nghiện bắt đầu quen dần với sự sựt giảm nồng độ nicotin trong máu khi áp dụng phương pháp cai thiệp thì các triệu chứng cai bắt đầu giảm. Và đến ngày 30 các chỉ số này chỉ còn: thèm thuốc $12.5 \%$, giảm tập trung $0.5 \%$, tăng cân $2.5 \%$, mất ngủ còn $3.5 \%$, đau đâu $1 \%$, ho $1 \%$.
4.2. Thay đổi nồng độ khí Co. Kết quả bảng 3.30 ta thấy nồng độ khí $\mathrm{CO}$ trong hơi thở bệnh nhân giảm rõ rệt trong quá trình điều trị. Chỉ sau 07 ngày điều trị, nồng độ khí $\mathrm{CO}$ giảm xuống từ $16.74 \pm 3.41$ ngày đâuu tiên xuống còn $14.38 \pm 3.35$ và đến ngày 30 thì chỉ số này chì còn $7.72 \pm 3.66$. Kết quả này có ý nghĩa thống kê trước với $p$ sau 7 ngày và $p$ trước sau điều trị đều $<0.05$. Điều này có thể giải thích do nồng độ CO trong hơi thở tương quan thuận với số điếu thuốc hút hàng ngày nên việc giảm được số điếu thuốc hút hàng ngày sau điều trị kéo theo việc giảm nồng độ $\mathrm{CO}$ trong hơi thở. Kết quả nồng độ $\mathrm{CO}$ trong hơi thở cũng được chúng tôi sử dụng ở những thời điểm khám lại và tư vấn. Các đối tượng được nhìn thãy chỉ số khác biệt rõ rệt ngay sau những nỗ lực bỏ thuốc lá đầu tiên giúp họ củng cố và có thểm động lực để tiếp tục điều tri.

4.3. Kết quả điêu trị cai nghiện thuốc lá. Hiệu quả cai nghiện thuốc lá bằng trà nhúng $B T L$ đạt tỷ lệ 38\% tốt, $25 \%$ khá và 37\% không kết quả.

Điều này cho thấy nếu có quyết tâm cai nghiện cao cùng với việc tuân thủ điêu trị thì kết quả cai nghiện rất tốt thể hiện qua sự cải thiện nồng độ đo khí $\mathrm{CO}$ và các triệu chứng lâm sàng của hội chứng cai như thèm thuốc, lo lắng, căng thẳng, cáu gắt...

4.4. Tác dụng không mong muốn của phương pháp can thiệp. Theo dõi trong quá trình nghiên cứu của chúng tôi không ghi nhận có các tác dụng không mong muốn như mẩn ngứa dị ứng, nôn và buiôn nôn, rối loạn tiêu hóa hay bất kỳ tai biến nào khác xảy ra.

\section{KẾT LUẬN}




\subsection{Hiệu quả trong điêu trị:}

- Giảm các triệu chứng khó chịu của hội chứng cai, giảm số lần và mức độ thèm muốn hút thuốc, giảm các triệu chứng ho, đau rát họng sau 30 ngày điều trị

- Giảm nồng độ CO trong hơi thở từ $16.74 \pm$ 3.41(ppm) xuống còn 7.72 $33.66(\mathrm{ppm})(\mathrm{p}<0,05)$.

- Hiệu quả cai nghiện thuốc lá của trà nhúng BTL theo nồng độ $\mathrm{CO}$ trong hơi thở đạt tỷ lệ $38 \%$ tốt, $25 \%$ khá và $37 \%$ không kết quả.

- Hiệu quả cải thiện các triệu chứng của hội chứng cai theo thang điểm MPSS đạt tỷ lệ $31.0 \%$ tốt, $43.5 \%$ khá, $22.0 \%$ trung bình và $3.5 \%$ kém.

\subsection{Tác dụng không mong muốn}

- Trà nhúng BTL không làm thay đổi nhịp tim, huyết áp và các chỉ số xét nghiệm máu, sinh hóa máu, nước tiểu trước và sau khi điều trị.

- Trong quá trình nghiên cứu, không xuất hiện tác dụng không mong muốn nào của phương pháp can thiệp trên lâm sàng, cho thây đây là phương pháp an toàn cho bệnh nhân.

\section{TÀI LIÊU THAM KHẢO}

1. Bộ Y Tế, WHO (2015). Điều tra toàn câu về hút thuốc lá ở người trưởng thành tai Viêt Nam (Global Adult Tobacco survey - GATS).

2. Lương Ngọc Khuê (2015). Hướng dẫn xây dựng cơ sở y tế không khói thuốc lá, Nhà xuất bản Y học Hà Nội.

3. Vũ Văn Giáp, Nguyễn Hải Anh, Phan Thanh Thủy (2015). Kiến thức, thái độ và hành vi về thuốc lá, thuốc lào của bệnh nhân tại Trung tâm Hô hấp Bệnh viện Bạch Mai. Tạp chí Y học Việt Nam, tháng 2, $149-153$.

4. Văn Thi Thu Hà (2018), "Nghiên cứu tính an toàn trên thực nghiệm cưa viên CTL và tác dụng lâm sàng kểt hợp tư vấn trong điều tri nghiên thuốc lá", Luận văn Thạc sĩ Y học, Đại học Y Hà Nội.

5. U.S. Department of Health and Human Services (2014). The health consequences of smoking - 50 years of progress: A report of the Surgeon General. Atlanta: U.S Department of Health and Human Services, Centers for Disease Control and Prevention, National Center for Chronic Disease Prevention and Health Promotion, Office on Smoking and Health.

6. WHO (2007). The European tobacco control report.

\title{
CÁC THUộC TÍNH CỦA MUỐI THẢO DƯợC NGÂM CHÂN ĐÁP ỨNG KỲ VỌNG CỦA NGƯỜI SỬ DƯNG TAI THÀNH PHỐ HỒ CHÍ MINH: MộT NGHIÊN CỨU MỐ TẢ CẮT NGANG
}

\author{
Lê Đặng Tú Nguyên ${ }^{1}$, Đặng Thị Kiều Nga ${ }^{1}$, Trần Thị Hồng Nguyên ${ }^{1}$,
} Lê Thị Trang1, Đặng Lưu Việt Quý1, Thái Tú Minh Phương1, Võ Quang Huy ${ }^{1}$, Ngô Thị Hồng Uyên ${ }^{2}$, Lê Minh Quân ${ }^{1 *}$

\section{TÓM TẮT}

Mục tiêu: Khảo sát các thuộc tính mong đợi của người sử dụng sản phẩm muối thảo dược ngâm chân và đánh giá sự hài lòng của người sử dựng đối với sản phẩm thứ nghiệm tại TPHCM. Đối tượng và phương pháp: Nghiên cứu mô tả cắt ngang, khảo sát các thuộc tính của muối thảo dược trên 512 người sử dụng và sự hài lòng của 300 người sau 30 ngày sử dụng. Kết quả: Các thuộc tính được người sử dụng kỳ vọng ở sản phẩm muối thảo dược ngâm chân được đưa vào sản phẩm thử nghiệm là màu nâu $(21,88 \%)$; mùi sả chanh $(19,53 \%)$; đóng gói đơn liều, trong hộp giấy và chứa nhiêu túi zipper nhỏ $(57,81 \%)$; giá thành từ $100.000-150.000$ VND cho liêu trình sứ dung 30 ngày $(51.76 \%)$; nhiệt độ nước ngâm chân là $30-38^{\circ} \mathrm{C}$ $(65,23 \%)$, khoảng thời gian ngâm chân phù hợp là 20

\footnotetext{
${ }^{1}$ Đai học Y Dược thành phố Hồ Chí Minh

${ }^{2}$ Trường Đai hoc Kỹ thuât Y-Dước Đà Nã̃ng

Chịu trách nhiệm chính: Lê Minh Quân

Email: leminhquan@ump.edu.vn

Ngày nhận bài: 10.9.2021

Ngày phản biên khoa hoc: 8.11 .2021

Ngày duyệt bài: 15.11.2021
}

phút $(53,32 \%)$. Sản phẩm thử nghiệm đã đáp ứng được nhu câuu của người sử dụng về các thuộc tính cơ bản của môt sản phẩm muối thảo dước ngâm chân với mức độ hài lòng ở mức "Rất hài lòng" (4-5 điểm). Kết luân: Kết quả khảo sát người sử dụng về các thuộc tính cơ bản của sản phẩm muối thảo dược ngân châm thử nghiệm sẽ là tiền đề cơ bản, góp phần hoàn thiện chế phẩm trước khi thương mại hóa một cách hiệu quả và đáp ứng được nhu cầu của người sử dụng.

Từ khóa: muối thảo dược, ngâm chân, thành phố Hồ Chí Minh

\section{SUMMARY \\ SURVEYING THE ATTRIBUTES OF HERBAL SALT FOR FOOT BATH MEETING CONSUMERS' EXPECTATIONS IN HO CHI MINH CITY \\ Objective: Survey the expected attributes of consumers in Ho Chi Minh City about herbal salt for foot bath and assess consumer satisfaction with the test products. Subjects and methods: A cross- sectional descriptive study surveying consumers' expected attributes and satisfaction for the test products. Results: The attributes expected by consumers in the herbal salt for foot bath included in the test product were brown $(21.88 \%)$; smell of}

